University of Wollongong

Research Online

Faculty of Engineering and Information

Faculty of Engineering and Information

Sciences - Papers: Part B

Sciences

2020

\title{
Effect of geogrid reinforcement on the strains at compressive zone of concrete pavements
}

Abbas Sahib Abd-Ali Al-Hedad

asaa774@uowmail.edu.au

Muhammad N. S Hadi

University of Wollongong, mhadi@uow.edu.au

Follow this and additional works at: https://ro.uow.edu.au/eispapers1

Part of the Engineering Commons, and the Science and Technology Studies Commons

Research Online is the open access institutional repository for the University of Wollongong. For further information contact the UOW Library: research-pubs@uow.edu.au 


\title{
Effect of geogrid reinforcement on the strains at compressive zone of concrete pavements
}

\author{
Abstract \\ (C) 2020 fib. International Federation for Structural Concrete The current study investigated the effect of \\ geogrid reinforcement on the fatigue behavior of concrete beam specimens in terms of the development \\ of strains at the compressive zone. The concrete beam specimens having the dimensions of $150 \mathrm{~mm} \times$ \\ $150 \mathrm{~mm} \times 550 \mathrm{~mm}$ were either unreinforced, reinforced with one layer of triaxial geogrid or reinforced \\ with two layers of triaxial geogrid. The strains at the compressive zone of specimens were measured \\ using strain gauges (SGs) fixed at two locations. The SGs of the first location were placed at the top of \\ the specimens. The SGs of the second location were placed at $13 \mathrm{~mm}$ from the top of the specimens. The \\ concrete beam specimens were tested under cyclic four-point bending loads with a frequency of $7 \mathrm{~Hz}$. \\ The cyclic four-point bending loads were carried out under a load control with a sinusoidal waveform for \\ several stress levels. Test results indicated that triaxial geogrid reduced the average strains at the \\ compressive zone by about $16 \%$ of the concrete beam specimens reinforced with one layer of geogrid \\ and by about $25 \%$ of the concrete beam specimens reinforced with two layers of geogrid in comparison \\ with unreinforced concrete beam specimens. The average rate of strain development at the compressive \\ zone of geogrid reinforced concrete beam specimens was significantly lower than that of the \\ unreinforced concrete beam specimens. In addition, the strains at the compressive zone of the concrete \\ beam specimens reduced with increasing the number of geogrid layers.

\section{Disciplines} \\ Engineering | Science and Technology Studies

\section{Publication Details}

Al-Hedad, A. \& Hadi, M. (2020). Effect of geogrid reinforcement on the strains at compressive zone of concrete pavements. Structural Concrete, 


\section{Effect of Geogrid Reinforcement on the Strains at Compressive Zone of}

\section{Concrete Pavements}

Abbas Sahib Abd-Ali Al-Hedad'; Muhammad N. S. Hadi', *

${ }^{1} \mathrm{PhD}$, School of CME Engineering, University of Wollongong, Wollongong, NSW 2522 ,

Australia. Email: asaa774@,uowmail.edu.au, Dhttps://orcid.org/0000-0003-4024-335X

2, *Associate Professor, School of CME Engineering, University of Wollongong, Wollongong,

NSW 2522, Australia (Corresponding author). Email: mhadi@uow.edu.au, 0000-0002$6490-889 X$

Running head: Effect of Geogrid on the Strains at Compressive Zone of CP 


\begin{abstract}
The current study investigated the effect of geogrid reinforcement on the fatigue behavior of concrete beam specimens in terms of the development of strains at the compressive zone. The concrete beam specimens having the dimensions of $150 \mathrm{~mm} \times 150 \mathrm{~mm} \times 550 \mathrm{~mm}$ were either unreinforced, reinforced with one layer of triaxial geogrid or reinforced with two layers of triaxial geogrid. The strains at the compressive zone of specimens were measured using strain gauges fixed at two locations. The strain gauges of the first location were placed at the top of the specimens. The strain gauges of the second location were placed at $13 \mathrm{~mm}$ from the top of the specimens. The concrete beam specimens were tested under cyclic four-point bending loads with a frequency of $7 \mathrm{~Hz}$. The cyclic four-point bending loads were carried out under a load control with a sinusoidal waveform for several stress levels. Test results indicated that triaxial geogrid reduced the average strains at the compressive zone by about $16 \%$ of the concrete beam specimens reinforced with one layer of geogrid and by about $25 \%$ of the concrete beam specimens reinforced with two layers of geogrid in comparison with unreinforced concrete beam specimens. The average rate of strain development at the compressive zone of geogrid reinforced concrete beam specimens was significantly lower than that of the unreinforced concrete beam specimens. In addition, the strains at the compressive zone of the concrete beam specimens reduced with increasing the number of geogrid layers.
\end{abstract}

KEYWORDS: triaxial geogrid; concrete pavements; cyclic loads; geosynthetic materials; bridges; strains; crack growth; concrete fatigue

\title{
1. INTRODUCTION
}

Concrete has excellent properties in compression. Concrete structures such as concrete pavements and deck slabs of bridges are designed to resist repeated loads. Repeated loads over the service life cause internal structural permanent changes resulting in fatigue damage of concrete structures. ${ }^{1-7}$ These changes continuously grow from the tensile region (from the bottom of concrete pavements) to the compressive region (to the top of concrete pavements). 
With the exposure of concrete pavements to repeated loads, the internal permanent changes develop to create microcracks. The microcracks gradually propagate and develop to macrocracks. As a result, the mechanical properties of concrete including compressive strength, load bearing capacity and the service life are reduced. The fatigue resistance of concrete pavements and deck slabs of bridges due to repeated loads also deteriorate.

Fatigue may also be the main reason for the failure of concrete pavements reinforced with steel bars or steel meshes. Over service time, the microcracks in the concrete pavements reinforced with steel bars or steel meshes propagate, thus allowing surface water to penetrate the concrete pavement through these microcracks. The functional role of steel bars or steel meshes in the concrete pavements declines due to corrosion. Flexural strength of steel reinforced concrete pavements deteriorates and, with not enough maintenance; the concrete pavements may be out service.

Geogrid is a geosynthetic material. ${ }^{8,9}$ Geogrid is manufactured from propylene composite materials. It is used for stabilizing weak soils, landfill and subbase for the constructions of roads and railways. ${ }^{10-12}$

Different kinds of geogrid such as uniaxial, biaxial and triaxial geogrid have been recently tested as a reinforcement or confinement material for Portland cement concrete elements such as beams, slabs and cylinders. ${ }^{13}$ Meski and Shehab ${ }^{14}$, Shobana and Yalamesh ${ }^{15}$, Siva Chidabram and Agarwal ${ }^{16}$, Tang et al. ${ }^{17}$, and Ramakrishnan et al. ${ }^{18}$ investigated the flexural behavior of concrete beams reinforced or confined with geogrid. They reported that the geogrid reinforcement improved the mechanical properties such as flexural strength and tensile strength of concrete beams reinforced with geogrid. Siva Chidabram and Agarwal ${ }^{13}$ and Tang et al. ${ }^{17}$ also illustrated that geogrid reinforcement delayed the collapse failure of concrete beams. Al- 
Hedad and $\mathrm{Hadi}^{19}$, Al-Hedad et al. ${ }^{20}$ and Al-Hedad and Hadi ${ }^{21}$ illustrated that the load capacity and the drying shrinkage resistance of concrete slabs reinforced with triaxial geogrid increased. In addition, they reported that the propagation of cracks in the concrete slabs reinforced with geogrid took a long time before the cracks completely developed. In addition, Hadi and Al$\operatorname{Hedad}^{22}$ have recently conducted an experimental study of fatigue performance of concrete specimens reinforced with geogrid. They illustrated that the fatigue performance including the loading capacity and resisting crack propagation of concrete specimens reinforced with geogrid are considerably improved. Siva Chidambaram and Agarwal $^{23}$ and Wang et al. ${ }^{24}$ studied the effect of geogrid on the compressive strength of concrete cylinders. They reported that the compressive strength of concrete cylinders confined with geogrid increased. Al-Hedad et al. ${ }^{25}$ reported the experimental results of the effect of geogrid materials on the thermal movements of the geopolymer concrete including the drying shrinkage and the thermal expansion under ambient conditions. They demonstrated that the geogrid could increase the resistance of geopolymer concrete reinforced with geogrid against the thermal movements.

As illustrated in the literature review, the applications of geogrid products in Portland cement concrete members are clearly increased. This study is a step in this direction. The current study investigates the influence of geogrid on the fatigue behavior of concrete beam specimens by investigating the development of strains at the compressive zone of the notched concrete beam specimens reinforced with geogrid.

\section{EXPERIMENTAL PROGRAM}

The experimental program included testing three groups of concrete beam specimens. The first group was unreinforced and taken as references. The second and third groups of concrete beam specimens were reinforced with one layer and two layers of geogrid, respectively. 


\subsection{Text Matrix}

Table 2 lists details of test matrix that conducted in this study. Three groups of concrete beams specimens were tested. The dimensions of the concrete beam specimens were $150 \mathrm{~mm} \times 150$ $\mathrm{mm} \times 550 \mathrm{~mm}$. The first group, called Group UC, consisted of five unreinforced concrete beam specimens (Beams $\mathrm{UC}_{1,2,3,4,5}$ ). The second group of concrete beam specimens were reinforced with one layer of geogrid and called Group GC, (Beams $\left.\mathrm{GC}_{1,2,3,4,5}\right)$. The third group of concrete beam specimens, Group 2GC, were reinforced with two layers of geogrid and symbolled as Beams $2 \mathrm{GC}_{1,2,3,4,5}$ (Table 2). The triaxial geogrid was used as a reinforcing material and placed at a depth of $55 \mathrm{~mm}$ from the bottom of concrete beam specimens. A notch at the middle of the bottom of the concrete beam specimens was made. The width and length of the notch were 3 $\mathrm{mm}$ and $40 \mathrm{~mm}$, respectively.

The concrete beam specimens used in this experimental study were prepared with normal strength concrete using Portland cement, Type general purpose, $\left(169 \mathrm{~kg} / \mathrm{m}^{3}\right)$, coarse aggregate with a maximum size of $10 \mathrm{~mm}\left(820 \mathrm{~kg} / \mathrm{m}^{3}\right)$ and fine sand $\left(332 \mathrm{~kg} / \mathrm{m}^{3}\right)$. The supplementary cementitious materials included fly ash $\left(68 \mathrm{~kg} / \mathrm{m}^{3}\right)$ and ground granulated blast furnace slag $\left(102 \mathrm{~kg} / \mathrm{m}^{3}\right)$ were used as a partial replacement of Portland cement. The water reducing admixture $\left(1525 \mathrm{ml} / \mathrm{m}^{3}\right)$, Type WRDA-PN20, was used in mixing the components of concrete mixture. ${ }^{26}$ The water-reducing admixture was added to achieve the appropriate workability for the concrete mixture. The workability for the concrete mixture used for casting the concrete specimens reinforced with geogrid is very important. This is to ensure the flows of the concrete mixture through the openings of the geogrid layers. The ratio of water to binder was 0.45 . The slump of fresh concrete mixture was $150 \mathrm{~mm}$.

Plywood molds having internal dimensions of $150 \mathrm{~mm} \times 150 \mathrm{~mm} \times 550 \mathrm{~mm}$ were used in this study to cast the concrete of beam specimens. Five plywood molds for each group of the 
concrete beam specimens (Groups UC, GC and 2GC) were fabricated, as shown in Figure 1. The level of triaxial geogrid reinforcement layer was located inside the plywood molds using a marker pen, Red in color. The steps that were followed in casting the concrete mixture of the specimens reinforced with triaxial geogrid were performed as follows. The first layer of concrete mixture was poured to a depth of $53 \mathrm{~mm}$. The triaxial geogrid layer was placed at the required level with a slight pressure. The first layer of concrete mixture with the triaxial geogrid layer was compacted with a light vibration. The plywood molds were filled with the second layer of concrete mixture. The plywood molds including the concrete mixture and the triaxial geogrid layer were compacted using a table vibrator. ${ }^{27}$ The placement of geogrid was checked after the test was completed for each tested specimen. The placement of geogrid was measured using a steel ruler. The measurements showed that all geogrids were located at the required level. A pointed concrete float made of steel was used for levelling the surface of the concrete mixture.

In order to determine the mechanical properties of the concrete, such as compressive strength and flexural strength, three cylinders of $100 \mathrm{~mm}$ diameter and $200 \mathrm{~mm}$ height, were cast and tested according to the requirements of AS 1012.9:20. ${ }^{28}$ After one day of casting, concrete cylinders were taken out of the molds and cured in water with a standard temperature of $23 \pm 2^{\circ}$ $\mathrm{C}$ for 27 days. The average compressive strength of concrete at the age of 28 days was $40 \mathrm{MPa}$. The average flexural strength of concrete was determined according to the recommendations reported by Austroads ${ }^{29}$ and found to be $4.7 \mathrm{MPa}$.

\subsection{Properties of Triaxial Geogrid}

Triaxial geogrid having the inside dimensions of $36 \mathrm{~mm} \times 36 \mathrm{~mm} \times 36 \mathrm{~mm}$ was used in this study, as shown in Figure 2. The ribs and nodes of the triaxial geogrid were manufactured from polypropylene composite materials. ${ }^{30,31}$ The average thickness and width of the ribs of the 
triaxial geogrid were $1.53 \mathrm{~mm}$ and $2.0 \mathrm{~mm}$, respectively; which were measured at the middle of length of the rib. The average thickness and diameter of nodes of the triaxial geogrid were $3.5 \mathrm{~mm}$ and $10.5 \mathrm{~mm}$, respectively.

Three samples in the machine direction and three samples in the cross-machine direction of the triaxial geogrid were prepared and tested in this study. This was done to determine the properties of the triaxial geogrid. As listed in Table 1, the average width and length of three samples of the triaxial geogrid tested in the machine direction were $255 \mathrm{~mm}$ and $127 \mathrm{~mm}$, respectively. The average width and length of three samples of the triaxial geogrid tested in the crossmachine direction were $262 \mathrm{~mm}$ and $131 \mathrm{~mm}$, respectively. The dimensions and the procedure of the tensile tests of the triaxial geogrid samples were performed according to the requirements of BS EN ISO $10319 .{ }^{32}$ The triaxial geogrid samples were tested under a strain rate of $20 \%$ per minute up to rupture.

Tensile tests of the triaxial geogrid samples were carried out using an Instron universal testing machine, Model 8033, having a capacity of $500 \mathrm{kN}$. The tensile tests of the triaxial geogrid samples were carried out at the laboratories of the School of Civil, Mining and Environmental Engineering at the University of Wollongong, Australia.

Tensile results of the triaxial geogrid samples are listed in Table 1. They showed that the average maximum load of triaxial geogrid samples tested in the machine direction was $6.9 \mathrm{kN}$ and 5.1 $\mathrm{kN}$ for the triaxial geogrid samples tested in the cross-machine direction. The average strains at the maximum load of the triaxial geogrid samples tested in the machine and cross-machine directions were $14.2 \%$ and $10.6 \%$, respectively.

The average secant modulus at $5 \%$ strain of the triaxial geogrid samples was $2.6 \%$ for the 
triaxial geogrid samples tested in the machine direction and $2.5 \%$ for the triaxial geogrid samples tested in the cross-machine direction. The concrete beam specimens tested in this study were reinforced with placing the triaxial geogrid layer in the cross-machine direction.

\subsection{Preparation of Strain Gauges}

Four types of strain gauges were used in this study to measure the strains at the compressive zone of the concrete beam specimens. As listed in Table 3, they included Types PL-120-11, PFL-30-11, PFL-20-11 and BX120-5AA. These types of the strains gauges were supplied by Tokyo Sokki Kenyujo Company, Ltd. ${ }^{33}$ The first type of strain gauges (Type PL-120-11) had a length of $120 \mathrm{~mm}$ with a gauge factor of $2.11 \pm 1 \%$. The second type of strain gauges (Type PFL-30-11) had a length of $30 \mathrm{~mm}$ and a gauge factor of $2.08 \pm 1 \%$. The third type (Type PFL20-11) and the fourth type of strain gauges, Type BX120-5AA, had a length of $20 \mathrm{~mm}$ and 30 $\mathrm{mm}$, respectively. The gauge factors of both the third and the fourth types of strain gauges were $2.08 \pm 1 \%$.

The strain gauges were fixed at two locations of the concrete beam specimens (compressive zone), as shown in Figures 3 and 4. At the first location, the strain gauges were fixed at the top surface of the concrete beam specimens, called $\mathrm{SG}_{\text {top }}$ (Figures 3 and 4 (a)). The second location of the strain gauges was at $13 \mathrm{~mm}$ from the top of the concrete beam specimens, called $\mathrm{SG}_{13}$ (Figures 3 and $4(b)$ ).

The preparation of location of the strain gauges was conducted according to the installation procedure reported by Catalog TML for standard strain gauges. ${ }^{33}$ The positions of strain gauges, called bonding areas hereafter, were located at the top and at $13 \mathrm{~mm}$ from the top of the concrete beam specimens. The positions of strain gauges were marked using a marker pen and taken as a guide mark. 
The bonding areas of strain gauges were cleaned using a brush and a cleaning tissue. The cleaning process of the bonding areas continued until the dust on the surface of the concrete was removed. An Araldite epoxy, Parts A and B, was used as an epoxy resin. ${ }^{34}$ Parts A and B of the Araldite epoxy were mixed using a plate made of aluminum. Parts A and B mixture of the Araldite epoxy were spread equally and uniformly on the bonding areas. The bonding areas, which were covered by Parts A and B mixture of Araldite epoxy, was a larger than the area occupied by the strain gauges. The bonding areas with Parts A and B mixture of Araldite epoxy were left for 24 hours for the hardening purpose.

The strain gauges were bonded at the bonding areas of the concrete beam specimens using TML Strain Gauge Adhesive (Adhesive $\mathrm{CN}$ ), Series CN, as an adhesive substance. ${ }^{35}$ Adhesive CN was applied thinly and uniformly using an adhesive nozzle and spread over the back surface of strain gauges. The strain gauges with Adhesive $\mathrm{CN}$ were placed on the guide mark of the bonding areas of the concrete beam specimens with a light press down on the strain gauge for approximately 1 minute. Afterwards, the strain gauges were left for three days before starting the tests. The strain gauges were finally covered with an adhesive tape having a width of 18 $\mathrm{mm}$. The adhesive tape was used to protect the strain gauges from scratching as that may occur when moving or setting up of the concrete beam specimens.

The strain gauges were checked before and after the installation procedure using a Multimeter device. The checking process of the strain gauges indicated that the strain gauges were correctly working.

\section{TEST PROCEDURE}

In this study, the specimens of Groups $\mathrm{UC}, \mathrm{GC}$ and $2 \mathrm{GC}$ were tested under cyclic four-point bending loads with a frequency of $7 \mathrm{~Hz}$. The concrete beam specimens were tested under cyclic 
loading between the age of 150 days and the age of 350 days. The cyclic loading was applied with a sinusoidal waveform under various stress levels within a defined stress-range $S^{\min }$ to $S^{\max }$ up to failure, in which $S^{\text {min }}$ and $S^{\max }$ represent the minimum and maximum cyclic loads, respectively. At the first stress level, the specimens of Groups UC, GC and 2GC were subjected to the maximum cyclic load equal to $12.5 \mathrm{kN}$. At the second stress level, the specimens were tested with a maximum cyclic load of $13.0 \mathrm{kN}$. Afterwards, the specimens were subjected to the maximum cyclic loads of 14, 15, 16, 17, 18, 19, and $20 \mathrm{kN}$. Some specimens of Groups UC, GC and 2GC failed before reaching the maximum cyclic loads of 18,19 and $20 \mathrm{kN}$. The minimum cyclic loads $\left(S^{\min }\right)$ adopted in this test was equal to $15 \%$ of the maximum cyclic loads $\left(S^{\max }\right)$ for all stress levels. Wherefore, in regarding the development of strains at the compressive zone of the concrete beam specimens, the fatigue behavior of the concrete beam specimen reinforced with geogrid was investigated within the positive loading and unloading range.

The concrete beam specimens were subjected to 50000 cycles or more for each stress level. The total load cycles at failure applied for each specimen of Groups UC, GC and 2GC are listed in Table 3. During the testing, the strains at the compressive zone of the concrete beam specimens were measured simultaneously with applying the cyclic loads.

\section{TEST RESULTS}

The influence of triaxial geogrid on the fatigue behavior of concrete beam specimens in monitoring the strains measured at the compressive zone of the specimens reinforced with either one layer or two layers of triaxial geogrid were investigated. The strains at the compressive zone corresponding to the maximum cyclic load at the evaluated load cycle were measured and evaluated. Test results of concrete beam specimens reinforced with triaxial geogrid were compared with the test results of unreinforced concrete beams specimens. 


\subsection{Effect of Triaxial Geogrid on the Strains at Failure}

The effect of triaxial geogrid on the strains measured at the compressive zone of Groups UC, GC and 2GC specimens at failure were evaluated, as shown in Figure 5. The strains at failure of Groups UC, GC, and 2GC specimens were determined according to the expression of $\left\{S T_{(\text {fail })}^{T}=\sum_{j=1}^{j=S L} S T_{(\text {fail }) j}\left(S^{\max } / S^{\min }\right)_{j}\right\}$, in which $S^{\text {min }}$ and $S^{\text {max }}$ represent the minimum and maximum cyclic loads, respectively; of stress at level $j, \mathrm{ST}_{(f a i l) j}$ is the average strain at failure obtained from two or three test results of strains measured by $\mathrm{SG}_{\mathrm{top}}$ (at the top of the specimen) and/or $\mathrm{SG}_{13}$ (at a distance of $13 \mathrm{~mm}$ from the top of specimen) strain gauges at stress level $j$, $S T_{(\text {fail })}^{T}$ represents the total average strains measured at the compressive zone of each concrete beam specimen at failure, $S L$ represents the total stress levels of concrete beam specimen up to failure.

It can be seen that the average strains at the compressive zone of Groups UC and GC specimens were close. While the average strains at the compressive zone of Group 2GC specimens were lower than the average strains at the compressive zone of both Groups UC and GC specimens. This illustrates that the triaxial geogrid with a single reinforcement layer did not have an impact in reducing the strains at the compressive zone of concrete beam specimens under cyclic loads. Using two reinforcement layers of geogrid reduced the strains at the compressive zone of Group 2GC specimens when subjected to cyclic loads.

The reduction of the average strains at failure for Group 2GC specimens was $8.5 \%$ lower than the average strains at the compressive zone of Group UC specimens. The average strains at failure of Group 2GC specimens were lower than the average strains at failure of Group GC specimens by about $10 \%$.

The reduction of the average strains at failure at the compressive zone of the concrete beam 
specimens reinforced with triaxial geogrid leads to prolonging the service life of the concrete pavements under traffic loads.

\subsection{Effect of Triaxial Geogrid on the Strains-Maximum Cyclic Loads}

The effect of triaxial geogrids on the strains measured at the compressive zone versus maximum cyclic loads of Groups UC, GC and 2GC specimens was evaluated. The strains shown in Figure 6 represent the average strains measured at the compressive zone of the Groups UC, GC and 2GC specimens for each stress level up to failure.

It can mention that the strains at the compressive zone of Groups GC and 2GC specimens were lower than the average strains at the compressive zone of Group UC specimens. This occurred at the maximum cyclic loads of $12.5,13,15$ and $17 \mathrm{kN}$. While, the average strains at the compressive zone of Groups GC and 2GC specimens at the maximum cyclic loads of 14, and $16 \mathrm{kN}$ were higher than those of Group UC specimens. At the maximum cyclic load of $13 \mathrm{kN}$, the average strains of Group 2GC specimens were higher than those of Groups UC and GC specimens.

In general, it can be said that the average strains measured at the compressive zone of the concrete beam specimens reinforced with one layer or two layers of triaxial geogrid reduced in the range of 2.0 to 3.3 times lower than the average strains at the compressive zone of unreinforced concrete beam specimens. As shown in Figure 6, the average strains measured at

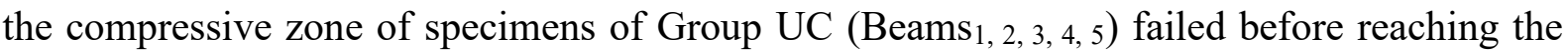
maximum cyclic loads of 18,19 , and $20 \mathrm{kN}$.

\subsection{Effect of Triaxial Geogrid on the Strains-Allowable Number of Load Cycles}

The effect of triaxial geogrid on the strains measured at the compressive zone versus the allowable number of load cycles of Groups UC, GC and $2 \mathrm{GC}$ is shown in Figure 7. According 
to the regime of cyclic loading tests that was followed in this study, the concrete beam specimens were subjected to 50000 cycles for each stress level up to failure (Table 3). The average strains at the compressive zone of Groups UC, GC, and $2 \mathrm{GC}$ specimens were determined by multiplying the average strains by the stress ratio for each stress level. The strains at the compressive zone, shown in Figure 7, represent the summation of the average strains at the number of load cycles $10,20,30,40$, and 50 cycles $(\times 1000)$.

It is apparent that the total strains measured at the compressive zone were lower at the number of cycles of 10, 20 and 40 cycles $(\times 1000)$ of Groups UC and GC specimens than the total strains of the specimens of Group 2GC. While the total strains measured at the compressive zone of Group 2GC specimens were lower at the number of cycles 50 cycles $(\times 1000)$ than those of the Groups UC and GC specimens.

The results shown in Figure 7 indicate that the effect of triaxial geogrid on the strains measured at the compressive zone appeared at higher levels of load cycles for the concrete beam specimens reinforced with two layers of triaxial geogrid.

\subsection{Effect of Triaxial Geogrids on the Development of Strains}

The effect of triaxial geogrids on the development of strains at the compressive zone of Groups UC, GC, and 2GC was investigated, as shown in Figure 8. The rate of development of the strains at the compressive zone of Groups UC, GC, and 2GC specimens was calculated by determining the difference between the strains measured at the first stress level and the strains measured at the failure stress level (last stress level of each concrete beam specimen). The results of strains between the first and failure stress levels for each concrete beam specimen was divided by the duration of cyclic loading tests $(\mathrm{sec})$. The average rate of strain development at the compressive zone, shown in Figure 8, represents the average rate of strain development 
measured at the compressive zone during the complete cyclic loading test of Groups UC, GC, and 2GC specimens.

Test results indicate that the triaxial geogrid reinforcement succeeded in reducing the average rate of the development of strains at the compressive zone of Groups GC and 2GC specimens. The decrease of the average rate of strains at the compressive zone was by about $90 \%$ for Group GC specimens and $96 \%$ for Group $2 \mathrm{GC}$ specimens lower than the average rate of strains at the compressive zone of Group UC specimens. In addition, the number of geogrid layers exhibited a significant resistance of the development of strains at the compressive zone of Group 2GC specimens (reinforced with two layers of triaxial geogrid) by about $60 \%$ lower than those of Group GC specimens (reinforced with one layer of triaxial geogrid).

\section{DISCUSSION}

In this study, the effect of triaxial geogrid on the fatigue behavior of notched concrete beam specimens relative to the development of strains at the compressive zone of the concrete beam specimens was investigated. The concrete beam specimens were tested under cyclic four-point bending loads with various stress levels. At each stress level, the concrete beam specimens were subjected to 50000 cycles up to failure. At each applied cyclic load, tensile stresses and strains created at the tensile zone of the concrete beam specimens (below the neutral axis). Simultaneously, compressive stresses and strains were generated at the compressive zone of concrete beam specimens.

As proven in a previous study, the triaxial geogrid could reduce the tensile stresses and strains of concrete beam specimens tested under cyclic loads. Test results in this study indicate that the triaxial geogrid participated in resisting the cyclic loads and improved the compressive strength of concrete against the strains that were generated in the compressive zone of concrete beam 
specimens plus the excellent compressive strength of concrete.

After many thousands of applied cyclic loads, microcracks in the concrete beam specimens initiated and distributed from the tension zone of the specimen towards the compressive zone. With existing cracks, the strain gauges fixed at the compression zone of the concrete beam specimens started recording the strains at the top of the compressive zone of the specimen. The strains increased with an increase of the applied cyclic loads together with the propagation of cracks. At this stage, the effect of geogrid on the development of strains at the compressive zone of the concrete beam specimen appeared. The test results obtained from this study illustrated that the geogrid exhibited a clear influence in reducing the strains created in the compressive zone. This may relate to the contribution of ribs of the geogrid embedded in the concrete in absorbing the pulsating loads which resulted from the applied cyclic loads. After many millions of applications of applied cyclic loads, microcracks rapidly propagated towards the compression zone of the concrete beam specimens. In general, the concrete beam specimens reinforced with geogrid exhibited a significant resistance against the development of strains at the compressive zone in comparison with the unreinforced concrete beam specimens. It can be mentioned that, with excellent compressive strength of concrete, the geogrid embedded in the tensile zone of the concrete beam specimens could succeed in reducing the strains at the compressive zone of the concrete beam specimens.

Reducing strains created at the compressive zone of the concrete structures reinforced with triaxial geogrid maintains the flexural behavior of the concrete structures against the fatigue damage for a long service time. In addition, the reduction of the strains at the compressive zone prolongs the fatigue life of the concrete structures before the failure took place. Increasing the number of triaxial geogrid layers exhibited a considerable effect in reducing the rate of development of the strains at the compressive zone of concrete specimens. 


\section{CONCLUSIONS}

The effect of triaxial geogrid on the strains created at the compressive zone of the notched concrete beam specimens reinforced with either one layer or two layers of triaxial geogrid were studied. The test results of the strains at the compressive zone of the concrete beam specimens were compared with the test results of the strains of the unreinforced concrete beam specimens. In general, the concrete beam specimens reinforced with triaxial geogrid exhibited lower strains at the compressive zone in comparison with the unreinforced concrete beam specimens. The main conclusions obtained from the test results of this study can be drawn as follows:

1. The geogrid exhibited a clear influence in reducing the strains created at the compressive zone of the concrete beam specimens when cracks are initiated in the concrete and before failure took place.

2. Geogrid significantly reduced the average strains created at the compressive zone of the concrete beam specimens reinforced with either one layer or two layers of geogrid when subjected to cyclic loads.

3. The effect of geogrid in reducing the strains at the compressive zone of the concrete beam specimens was appeared at all stress levels for the concrete beam specimens reinforced with one layer of geogrid and at higher stress levels for the concrete beam specimens reinforced with two layers of geogrid.

4. The number of geogrid layers used as a flexural reinforcing material of the concrete pavements subjected to wheel loads had a considerable influence in reducing the strains at the compressive zone in the comparison with the concrete pavements reinforced with one layer of geogrid. 
5. The reduction of strains at the compressive zone of concrete pavements results in improving the fatigue life and the serviceability conditions of the concrete pavements. In addition, the mitigation of strains generated at the compressive zone of concrete pavements reduces the costs required for the maintenance and the rehabilitation of concrete pavements.

\section{ACKNOWLEDGEMENTS}

The authors present acknowledgements to Senior Officers Mr Richard Gasser, Mr Duncan Best, and Richie Mclean and for all technical staff who work in the laboratories of the School of Civil, Mining and Environmental Engineering (CME), University of Wollongong, Australia. The first author would like to thank the Ministry of High Education and Scientific Research of Iraq, Iraq. Both authors thank the University of Wollongong, Australia for providing all necessary facilities to achieve this work. 


\section{REFERENCES}

1. BreitenbÜcher R, Ibuk H. Experimentally based investigations on the degradation-process of concrete under cyclic load. Mater Struct/Mater Construct 2006;39:717-724.

2. Mou, T, Ding Q, Zhou X., Fan B. Fatigue performance of steel fiber reinforced concrete bridge deck pavement. Wuhan Ligong Daxue Xuebao (Jiaotong Kexue Yu Gongcheng Ban)/Journal of Wuhan University of Technology (Transportation Science and Engineering) 2012;36:988-991.

3. Parvez A, Foster SJ. 2014. Fatigue behavior of steel-fiber-reinforced concrete beams. J Struct Eng (ASCE). 2014;141:1-8. DOI:10.1061/(asce)st.1943541x.0001074.

4. Susmel L. High-cycle fatigue of notched plain concrete. Procedia Structural Integrity. 2016;1:2-9.

5. Ugras RC, Alkan OK, Orhan S, Kutlu M, Mugan A. Real time high cycle fatigue estimation algorithm and load history monitoring for vehicles by the use of frequency domain methods. Mech Syst Sign Proc. 2019;118:290-304. DOI: https://doi.org/10.1016/j.ymssp.2018.08.043.

6. Hansen M. Determination and assessment of fatigue stresses on concrete bridges. Struct Concr. 2020;(in press). DOI: 10.1002/suco.201900432.

7. Dineshkumar M, Ramkumar S. Review paper on fatigue behavior of reinforced concrete beams. Mater Today. Proceedings 2020;21:19-23. DOI: 10.1016/j.matpr.2019.05.353.

8. Ling HI, Mohri Y, Kawabata T. Tensile properties of geogrids under cyclic loadings. J Geotech Geoenviron Eng. 1998;124:782-787.

9. Abu-Farsakh MY, Akond I, Chen Q. Evaluating the performance of geosynthetic-reinforced unpaved roads using plate load tests. Inter J Pav Eng. 2016;17: 901-912.

10. Chen Q, Abu-Farsakh M, Tao M. Laboratory evaluation of geogrid base reinforcement and corresponding instrumentation program. Geotech T J (ASTM). 2009;32(6):516-525.

11. Abu-Farsakh M, Chen Q. Evaluation of geogrid base reinforcement in flexible pavement using cyclic plate load testing. Intern J Pav Eng. 2011;12(3):275-288. DOI:10.1080/10298436.2010.549565.

12. Ziegler M. Application of geosynthetics in the construction of roads and railways: yesterday-today-tomorrow. Geotechnics of roads and railways: Proceedings of the $15^{\text {th }}$ Danube-European Conference on Geotechnical Engineering 2014: 9-11.

13. Zhang H, Hadi MNS Geogrid-confined pervious geopolymer concrete piles with FRP-PVCconfined concrete core: Concept and behavior. Construct Build Mater 2019;211:12-25. DOI: 10.1016/j.conbuildmat.2019.03.231. 
14. Meski FE, Chehab GR. Flexural behavior of concrete beams reinforced with different types of geogrids. J Mater Civ Eng (ASCE). 2014;26:1-8.

15. Shobana S, Yalamesh G. Experimental study of concrete beams reinforced with uniaxial and biaxial geogrids. Inter J ChemTech Res. 2015:8:1290-1295.

16. Siva Chidambaram R, Agarwal P. Inelastic behaviour of RC beams with steel fibre and polymer grid confinement. Indian Con J. 2015;89: 83-90.

17. Tang X, Higgins I, Jlilati M. behavior of geogrid-reinforced Portland cement concrete under static flexural loading. Infrastructures (MDPI). 2018;3(41):1-12. DOI:10.3390/infrastructures3040041.

18. Ramakrishnan S, Arun M, Loganayagan S, Mugeshkanna M. Strength and behaviour of geogrid reinforced concrete beams. Inter J Civ Eng Tech. 2018; 9:1295-1303.

19. Al-Hedad AS, Hadi MNS 2017. Flexural behaviour of concrete pavements reinforced with geogrid materials. 24th Australasian Conference on the Mechanics of Structures and Materials: Advancements and Challenges. Curtin University, Perth, Australia: 2017: Taylor \& Francis Group, London, ISBN 978-1-138-02993-4.

20. Al-Hedad ASA, Bambridge E, Hadi MNS. Influence of geogrid on the drying shrinkage performance of concrete pavements. Construct Build Mater. 2017;146:165-174.

21. Al-Hedad ASA, Hadi MNS. Effect of geogrid reinforcement on the flexural behaviour of concrete pavements. Road Mater Pav Des. 2019;20(5):1005-1025.DOI: 10.1080/14680629.2018.1428217.

22. Hadi MNS, Al-Hedad ASA. Flexural fatigue behaviour of geogrid reinforced concrete pavements. Construct Build Mater 2020;249:1-10.DOI: 10.1016/j.conbuildmat.2020.118762.

23. Siva Chidambaram R, Agarwal P. The confining effect of geo-grid on the mechanical properties of concrete specimens with steel fiber under compression and flexure. Construct Build Mater. 2014;71:628-637.

24. Wang W, Sheikh MN, Hadi MNS. Axial compressive behaviour of concrete confined with polymer grid. Mater Struct 2015;1-17.DOI: 10.1617/s11527-015-0761-9.

25. Al-Hedad ASA, Farhan NA, Zhang M, Sheikh MN, Hadi MNS, Effect of geogrid reinforcement on the drying shrinkage and thermal expansion of geopolymer concrete. (in English), Struct Concr 2019;(in press): 1-11. DOI: 10.1002/suco.201900299.

26. GCP Applied Technologies Dispersant Technology Water Reducer. gcpat.com, Inc. 62 Whittemore Avenue, Cambridge, MA 02140, USA. Last viewed on 20 June 2017, <https://gcpat-tools.com/construction/en-au/Documents/WRDA\%20PN20.pdf>.

27. SYNTRON Packer Syntron material handing. Model VP 85B, Made in Australia under Licence of Syntron Co., Homer City, PA., U.S.A, last viewed on 5 March 2017. 
28. AS 1012.9 Method of Testing concrete, Method 9: Compressive strength tests-concrete, mortar and grout specimens. Standards Australia, Sydney, Australia 2014.

29. Australia Pavement Design- A. Guide to the structural design of road pavements. Austroads Incorporated, ISBN 0855887028. No. PUB.PT.C.007 (T\& E.C.029), Sydney, NSW2000, Australia 2004.

30. AS 3704 Geosynthetics-glossary of terms. Australian Standard 3704, Committee CE-020, Sydney, NSW 2001, Australia, 2005.

31. Koerner RM. Cover \& Table of Contents - Designing with Geosythetics. $5^{\text {th }}$ Edition 2012.

32. BS EN ISO 10319 Geosynthetics-Wide-Width Tensile Test. BSI Standards Limited 2015: $1-14$.

33. TML Standard Strain Gauges Precise \& Flexible Strain Gauge: TML Standard Strain Gauges and Associated Products. Tokyo Sokki Kenyujo Co., Ltd, last viewed on July 2017, 180 .

34. Bunnings Group Limited Caitlin Meedan Trade Specialist. Lat 205 Gipps st., Wollongong, NEW 2500, Last viewed on June 2017, <Australiawollonongtrade @ bunnings.com.au>.

35. Bestech Australia Pty Ltd Cyanoacrylate Adhesive; CN Adhesive. Tokyo Sokki Kenkyuio Co., Ltd. Chome Shingawa-Tokyo 140-8560, last viewed on March 2017. 


\section{List of Tables}

TABLE 1 Properties of triaxial geogrid

TABLE 2 Text matrix

TABLE 3 Strain gauges 


\section{List of Figures}

FIGURE 1 Plywood molds of the specimens of Groups UC, GC and 2GC

FIGURE 2 Triaxial geogrid

FIGURE 3 Strain gauges $\mathrm{SG}_{\text {top }}$ and $\mathrm{SG}_{13}$ of the concrete beam specimen

FIGURE 4 Locations of strain gauges of (a) $\mathrm{SG}_{\text {top }}$ at the top fibre of concrete beam specimen, and (b) $\mathrm{SG}_{13}$ at $13 \mathrm{~mm}$ distance from the top of concrete beam specimens

FIGURE 5 Total average failure strains at the compressive zone of Groups UC, GC and 2GC specimens

FIGURE 6 Average failure strains at the compressive zone versus maximum cyclic loads of Groups UC, GC and 2GC specimens

FIGURE 7 Average failure strains at the compressive zone versus the allowable number of load cycles for each stress level of Groups UC, GC and 2GC specimens

FIGURE 8 Average rate of strain development at the compressive zone of Groups UC, GC, and 2GC specimens 
TABLE 1 Properties of triaxial geogrid

Properties of triaxial geogrid

Inside dimensions ( $\mathrm{mm}$ )

Average thickness of ribs (mm)

Average width of ribs (mm)

Average thickness of nodes (mm)

Average diameter of nodes (mm)

Average width of three triaxial geogrid samples (mm)

Average length of three triaxial geogrid samples (mm)

\section{Test results}

$36 \times 36 \times 36$

1.53

2.0

3.5

10.5

$\mathrm{MD}^{\mathrm{a}}$

$\mathrm{CMD}^{\mathrm{b}}$

255

262

127

Tensile results of three triaxial geogrid samples

Average maximum load $(\mathrm{kN})$

Average strains at maximum load (\%)

Average secant modulus at $5 \%$ strain (\% strain)
6.9

14.2

2.6
5.1

10.6

2.5

${ }^{\mathrm{a}}$ and ${ }^{\mathrm{b}}$ : are the test results of triaxial geogrid samples tested in the machine and cross-machine direction, respectively. 
TABLE 2 Text matrix

\begin{tabular}{ccccc} 
Groups & $\begin{array}{c}\text { Number of } \\
\text { specimens }\end{array}$ & $\begin{array}{c}\text { Labels of } \\
\text { specimens }\end{array}$ & $\begin{array}{c}\text { Dimensions of specimens } \\
(\mathbf{m m})\end{array}$ & $\begin{array}{c}\text { State of } \\
\text { reinforcement }\end{array}$ \\
\hline Group UC & 5 & Beams UC $_{1,2,3,4,5}$ & $150 \times 150 \times 550$ & $\begin{array}{c}\text { Unreinforced concrete } \\
\text { specimens } \\
\text { Reinforced with one } \\
\text { layer of geogrid }\end{array}$ \\
Group GC & 5 & Beams GC ${ }_{1,2,3,4,5}$ & $150 \times 150 \times 550$ & $\begin{array}{c}\text { Reinforced with two } \\
\text { layers of geogrid }\end{array}$
\end{tabular}


TABLE 3 Strain gauges

\begin{tabular}{|c|c|c|c|c|c|}
\hline Specimens & $\begin{array}{c}\text { Number of } \\
\text { strain gauges }\end{array}$ & $\begin{array}{c}\text { Type of strain } \\
\text { gauges }\end{array}$ & $\begin{array}{l}\text { Gauge length } \\
\text { (mm) }\end{array}$ & $\begin{array}{l}\text { Location of } \\
\text { strain gauge }\end{array}$ & $\begin{array}{c}\text { Number of } \\
\text { cycles }(\times 1000)\end{array}$ \\
\hline \multicolumn{6}{|c|}{ Specimens of Group UC } \\
\hline Beam $\mathrm{UC}_{1}$ & 2 & $\begin{array}{l}\text { PFL-30-11 } \\
\text { PFL-30-11 }\end{array}$ & $\begin{array}{l}30 \\
30\end{array}$ & \multirow{4}{*}{13 mm location $^{\mathrm{b}}$} & 412 \\
\hline Beam $\mathrm{UC}_{2}$ & 2 & $\begin{array}{l}\text { PFL-30-11 } \\
\text { PL-120-11 }\end{array}$ & $\begin{array}{c}30 \\
120\end{array}$ & & 59 \\
\hline Beam $\mathrm{UC}_{3}$ & 2 & $\begin{array}{l}\text { PFL-20-11 } \\
\text { PFL-20-1 }\end{array}$ & $\begin{array}{l}120 \\
20 \\
20\end{array}$ & & 136 \\
\hline Beam $\mathrm{UC}_{4}$ & 2 & $\begin{array}{l}\text { PL-120-11 } \\
\text { PL-120-11 }\end{array}$ & $\begin{array}{l}120 \\
120\end{array}$ & & 356 \\
\hline Beam $\mathrm{UC}_{5}$ & 3 & $\begin{array}{c}\text { PL-120-11 } \\
\text { PL-120-11 } \\
\text { BX120-5AA }\end{array}$ & $\begin{array}{l}120 \\
120 \\
30\end{array}$ & $\begin{array}{c}13 \mathrm{~mm} \text { location } \\
13 \mathrm{~mm} \text { location } \\
\text { Top location }^{\mathrm{c}}\end{array}$ & 219 \\
\hline \multicolumn{6}{|c|}{ Specimens of Group GC } \\
\hline Beam $\mathrm{GC}_{1}$ & 1 & $\begin{array}{l}\text { PL-120-11 } \\
\text { PL-60-11 }\end{array}$ & $\begin{array}{c}120 \\
60\end{array}$ & $13 \mathrm{~mm}$ location & 708 \\
\hline Beam $\mathrm{GC}_{2}$ & 2 & PL-120-11 & 120 & $13 \mathrm{~mm}$ location & 95 \\
\hline Beam $\mathrm{GC}_{3}$ & 2 & $\begin{array}{l}\text { PL-120-11 } \\
\text { PFL-30-11 }\end{array}$ & $\begin{array}{c}120 \\
30\end{array}$ & $13 \mathrm{~mm}$ location & 214 \\
\hline Beam $\mathrm{GC}_{4}$ & 3 & $\begin{array}{l}\text { PL-120-11 } \\
\text { PL-120-11 } \\
\text { PL-60-11 }\end{array}$ & $\begin{array}{c}120 \\
120 \\
60\end{array}$ & $\begin{array}{c}\text { 13mm-location } \\
\text { 13mm-location } \\
\text { Top location }\end{array}$ & 134 \\
\hline Beam $\mathrm{GC}_{5}$ & 3 & $\begin{array}{l}\text { PL-30-11 } \\
\text { PL-120-11 } \\
\text { PL-60-11 }\end{array}$ & $\begin{array}{c}30 \\
120 \\
60\end{array}$ & $\begin{array}{c}13 \mathrm{~mm} \text { location } \\
13 \mathrm{~mm} \text { location } \\
\text { Top location }\end{array}$ & 277 \\
\hline \multicolumn{6}{|c|}{ Specimens of Group 2GC } \\
\hline Beam $2 \mathrm{GC}_{1}$ & 2 & $\begin{array}{l}\text { PL-120-11 } \\
\text { PL-60-11 }\end{array}$ & $\begin{array}{c}120 \\
60\end{array}$ & $13 \mathrm{~mm}$ location & 373 \\
\hline Beam $2 \mathrm{GC}_{2}$ & 2 & $\begin{array}{l}\text { PL-120-11 } \\
\text { PL-60-11 }\end{array}$ & $\begin{array}{c}120 \\
60\end{array}$ & $13 \mathrm{~mm}$ location & 117 \\
\hline Beam $2 \mathrm{GC}_{3}$ & 3 & $\begin{array}{l}\text { PL-120-11 } \\
\text { PL-120-11 } \\
\text { PL-60-11 }\end{array}$ & $\begin{array}{c}120 \\
120 \\
60\end{array}$ & $\begin{array}{c}13 \mathrm{~mm} \text { location } \\
13 \mathrm{~mm} \text { location } \\
\text { Top location }\end{array}$ & 416 \\
\hline Beam $2 \mathrm{GC}_{4}$ & 3 & $\begin{array}{l}\text { PL-120-11 } \\
\text { PL-120-11 } \\
\text { PL-60-11 }\end{array}$ & $\begin{array}{c}120 \\
120 \\
60\end{array}$ & $\begin{array}{l}\text { 13mm-location } \\
13 \mathrm{~mm} \text {-location } \\
\text { Top location }\end{array}$ & 275 \\
\hline Beam $2 \mathrm{GC}_{5}$ & 3 & $\begin{array}{c}\text { PL-30-11 } \\
\text { PL-120-11 } \\
\text { PL-60-11 }\end{array}$ & $\begin{array}{c}30 \\
120 \\
60\end{array}$ & $\begin{array}{c}13 \mathrm{~mm} \text { location } \\
13 \mathrm{~mm} \text { location } \\
\text { Top location }\end{array}$ & 217 \\
\hline
\end{tabular}

